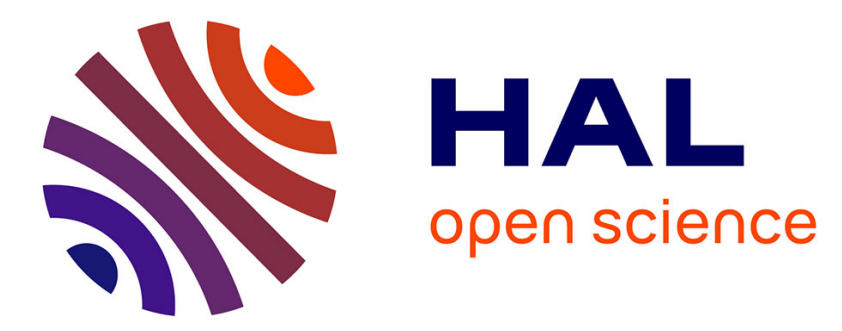

\title{
A Reflection Electron Microscopy Investigation of the Divergence of the Mean Correlated Difference of Step Displacements on a $\mathrm{Si}(111)$ Vicinal Surface
}

\author{
J. Heyraud, J. Bermond, Claude Alfonso, J. Métois
}

\section{- To cite this version:}

J. Heyraud, J. Bermond, Claude Alfonso, J. Métois. A Reflection Electron Microscopy Investigation of the Divergence of the Mean Correlated Difference of Step Displacements on a Si(111) Vicinal Surface. Journal de Physique I, 1995, 5 (4), pp.443-449. 10.1051/jp1:1995137 • jpa-00247069

HAL Id: jpa-00247069

https://hal.science/jpa-00247069

Submitted on 1 Jan 1995

HAL is a multi-disciplinary open access archive for the deposit and dissemination of scientific research documents, whether they are published or not. The documents may come from teaching and research institutions in France or abroad, or from public or private research centers.
L'archive ouverte pluridisciplinaire HAL, est destinée au dépôt et à la diffusion de documents scientifiques de niveau recherche, publiés ou non, émanant des établissements d'enseignement et de recherche français ou étrangers, des laboratoires publics ou privés. 
Classification

Physics Abstracts

68.30

\title{
Short Communication
}

\section{A Reflection Electron Microscopy Investigation of the Divergence of the Mean Correlated Difference of Step Displacements on a Si(111) Vicinal Surface}

\author{
J.C. Heyraud $\left(^{*}\right)$, J.M. Bermond $\left({ }^{* *}\right)$, C. Alfonso $\left({ }^{* * *}\right)$ and J.J. Métois \\ CRMC2-CNRS $\left(^{* * * *}\right.$ ), Campus Luminy, Case 913, 13288 Marseille Cedex 09, France
}

(Received 21 December 1994, accepted 24 January 1995)

\begin{abstract}
A Si(111) vicinal (misorientation $\approx 0.6$ ) is studied by in situ Reflection Electron Microscopy at $1173 \mathrm{~K}$. A statistical study is done of the distances between pairs of $m^{\text {th }}$ neighbours in a step train. The mean correlated difference of the step displacements from their mean positions $G(m)=\left\langle\left(u_{1}-u_{\imath+m}\right)^{2}\right\rangle$ is determined as a function of $m$. Evidence is given for the roughness of the surface. A logarithmic behaviour of $G(m)$ versus $m$ is demonstrated unambiguously up to $m=7$. Quantitative agreement is found with the theoretical predictions of Villain, Grempel and Lapujoulade. For more distant pairs of steps a different behaviour is demonstrated: $G(m)$ increases faster than $\log (m)$, a fact already found by another author.
\end{abstract}

\section{Introduction}

The roughening transition of a crystal surface has been the subject of many theoretical and experimental investigations. This transition can be detected through the behaviour of the mean correlated height difference $H\left(r_{\imath \jmath}\right)=\left\langle\left(h_{\imath}-h_{j}\right)^{2}\right\rangle$, where $h_{\imath}-h_{j}$ is the height difference of the surface (above some reference plane) between two points separated by a distance $r_{2 \jmath}$, measured parallel to the surface plane and where the brackets denote an ensemble average. At $T$ smaller than the roughening temperature $\left(T_{\mathrm{R}}\right), H\left(r_{\imath \jmath}\right)$ remains finite as $r_{\imath \jmath} \rightarrow \infty$, whereas it goes to infinity with $r_{2 j}$ at $T>T_{\mathrm{R}}$. In the latter case, theory predicts a logarithmic divergence with $r$ $([1,2]$ and references therein).

Experımental evidence for the logarithmic divergence was first deduced from $\mathrm{He}$ and $\mathrm{X}$-rays diffraction experıments on vicinal surfaces ( [3] and references therein). It is only indirect since

(*) Also Université de Provence (Aix-Marseille I), Marseille, France.

$\left({ }^{* *}\right)$ Corresponding author. Also Université de Droit, d'Economie et des Sciences d'Aix-Marseille (AixMarsellle III), Marsellle, France.

$\left({ }^{* * *}\right)$ Present address: Laboratoire de Métallurgie-URA 443, Université de Drott, d'Economie et des Sciences d'Aix-Marselle (Aix-Marselle III), Marselle, France.

$\left({ }^{* * * *}\right)$ Laboratoire propre du CNRS (LP7251), assocıé aux Universités d'Aix-Marsellle II et III.

(C) Les Editions de Physıque 1995 
Experimental evidence for the logarıthmic divergence was first deduced from He and X-rays diffraction experiments on vicinal surfaces ( [3] and references therein). It is only indirect since the only measurable parameters are the height and width of the diffraction peaks.

In order to check the roughening of the surface it is sufficient to measure the normal displacement $u_{2}$ of the $i^{\text {th }}$ step from its average position and to plot the quantity $G(m)=$ $\left.<\left(u_{r}-u_{\imath}+m\right)^{2}\right\rangle$ as a function of $m$ [2]. As shown in Figure 1, it is equivalent to determining the correlated height difference $H$ in the direction normal to the steps since $\left(h_{\imath}-h_{\imath+m}\right)^{2}=\sin ^{2} \theta\left(u_{\imath}-u_{\imath+m}\right)^{2}$, with $\theta$ the misorientation angle of the vicinal.

Direct observation of the step position is allowed by STM. $G(m)$ can then be calculated from the measurement of the deviations of the steps from their mean positions. Such measurements were attempted by Goldberg et al. [4], and, more recently, by Masson [5] and Hegeman et al. [6]. Golberg et al. investigated vicinal $\mathrm{Si}(111)$ surfaces below the $(7 \times 7)-(1 \times 1)$ surface transition temperature. Their experıments were made difficult by the imperfect equilibration of the surface (occurrence of triple-height steps). Yet, by averaging the data from different samples, a logarithmic law was found. However the authors did not compare the slope of their experimental straight line with the theoretically expected value. Hegeman et al. measured $G(m)$ on vicinal $\mathrm{Si}(100)$ surfaces. They did not find a logarithmic dependence of $G(m)$ on $m$. Instead they got a tendency to saturation with oscillations superimposed. Masson investigated a $(1,1,11)$ copper surface. Her data are compatible with a logarithmic law, however

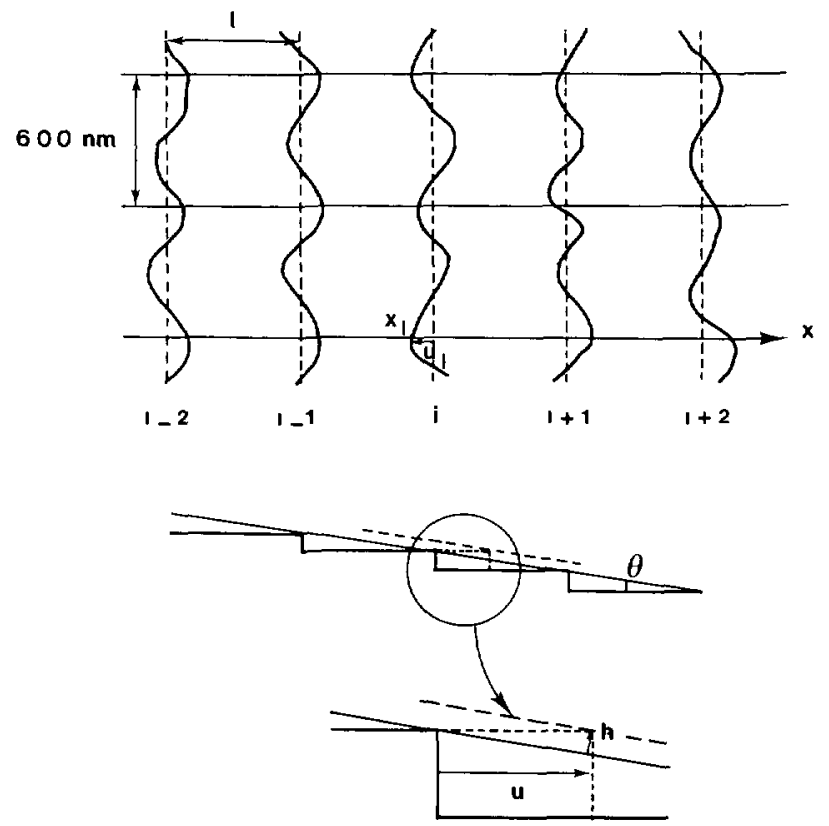

Fig. 1. - Schematic drawing of a meandering train of steps and definition of the parameters used in text. Top: View normal to the terrace plane. Doted lines: The mean positions of the steps, equally spaced by $(l)$. They are the zero temperature positions of the steps. The $x$-axis is parallel to the terrace plane and normal to the step mean direction. The three "sections" used in the measurements are parallel to the $x$-axis, $x_{2}$ is the position of the $i^{\text {th }}$ step. Bottom: Cross sectional view of the vicinal surface. The $0 \mathrm{~K}$ positions of the steps are drawn as solid lines. For clarity, the displacement of only one step is shown (doted line). 
only for small $m$ (i.e. for the first three consecutive terraces in a step train). For larger $m$ she found a more complex behaviour which she did not attempt to rationalise. It must be noted that all the above-mentioned experiments were done on vicinals that had rather closely spaced steps. This is necessary either in diffraction experiments, due to the coherence length of the diffracting beam, or in STM experiments where a sufficient number of images must be recorded to extract statistically significant information. Prerequisites to any verification of the theoretical expectations seems to be (i) the use of vicinals with large step distances and (ii) the measurement of a sufficient number of steps in the same train.

We checked the behaviour of $G(m)$ by using a $\mathrm{Si}(111)$ vicinal displaying a great number of rather loosely spaced steps. The experıments were done by in situ Reflection Electron Microscopy $(\mathrm{REM})$ at $1173 \mathrm{~K}$, i.e. above the reconstruction temperature of the $(7 \times 7)$. This paper reports our experimental results and compare them to the theoretical predictions of Villain, Grempel and Lapujoulade (VGL) [2].

\section{Experimental Results}

The experimental details have been explained elsewhere [7] and will not be repeated here. The sample temperature was $1173 \mathrm{~K}$. The region of the surface which was observed had a fairly uniform train of steps, about $30 \mathrm{~nm}$ apart, which corresponds to a misorientation angle $(\theta)$ of roughly $0.6^{\circ}$. Figure 1 shows a REM image of this sample. The mean step direction is $\langle 110\rangle$ and the steps are practically parallel to the electron beam incidence plane. Thus the image distorsion is negligible normal to the step direction. Hence, the $u_{\imath}$ 's can be directly measured. Figure 1 summarises the definitions.

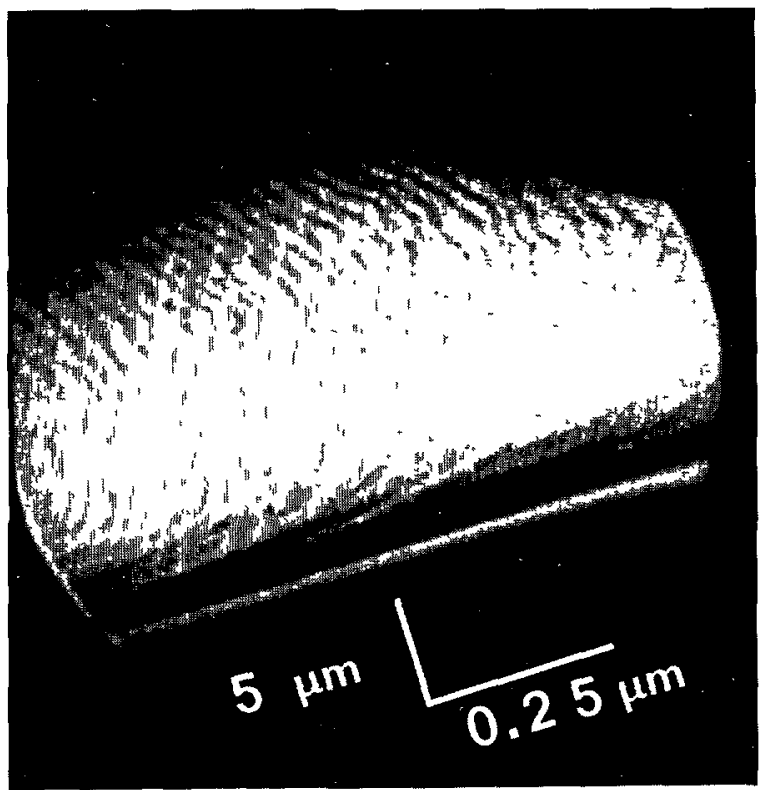

Fig. 2. - REM image of the step train that was studied. The incident electron beam is perpendicular to the $0.25 \mu \mathrm{m}$ bar. Since the image is severely foreshortened (compare the lengths of the scale bars), the steps are actually almost parallel to the electron beam incidence plane. 


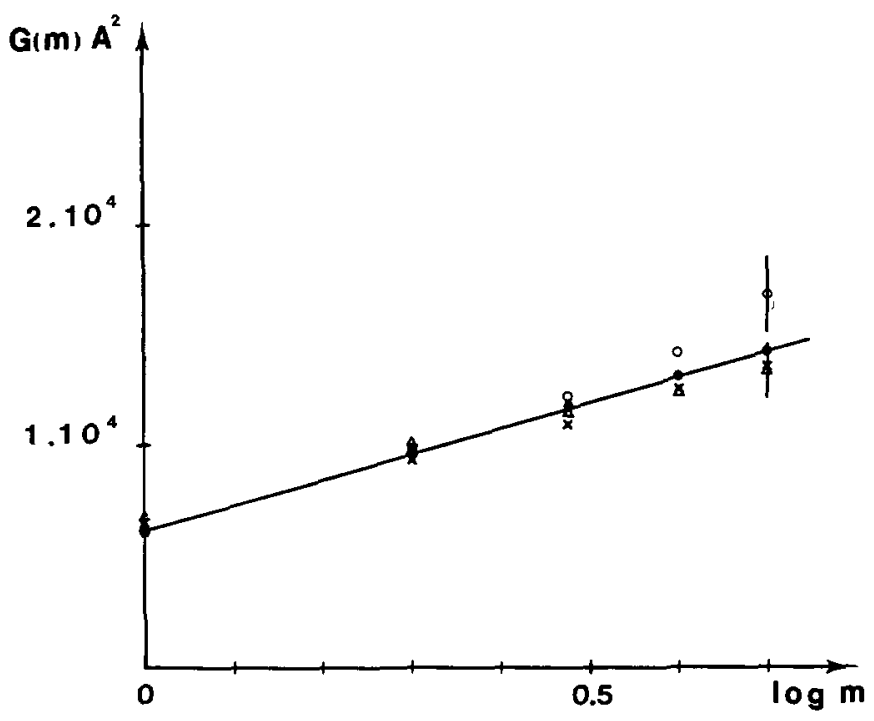

Fig. 3. $-G(m)$ versus $\log _{10}(m)$ for groups of 6 steps within the train of $16 .(0)$ : steps 1 to $6 .(\times)$ : steps 6 to $11 ;(\triangle)$ : steps 10 to 16. The solid line and the black dots $(\bullet)$ are extracted from Figure 4 to show that the slope is the same within the uncertainty of our measurements. For clarity, only a few error bars are drawn.

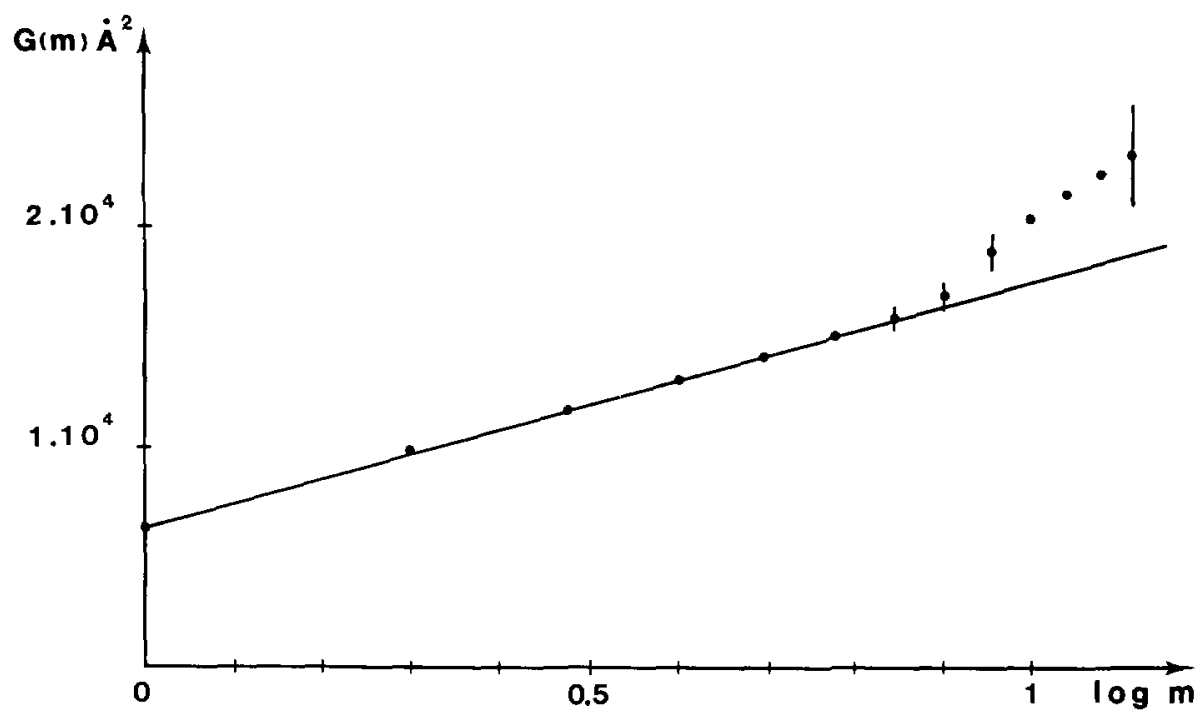

Fig. 4. $-G(m)$ versus $\log _{10}(m)$ for steps 1 to 14 . For clarity, only a few error bars are drawn.

We have studied a set of 16 consecutive steps in the train shown in Figure 2. An independent determination of the autocorrelation function of the step fluctuations showed that the autocorrelation length along the step direction is roughly $400 \mathrm{~nm}$ in this train [8]. Consequently three "sections" of the step train were made, normal to the average step direction, roughly $600 \mathrm{~nm}$ apart. The distances between couples of steps $\left(x_{\imath}-x_{\imath+m}\right)$ along these "sections" were 
Table I. - Mean step distances, numbers of pairs of first and most distant neighbours for the various portions of the step train that were studied.

\begin{tabular}{|c|c|c|c|}
\hline Step labels & $\begin{array}{c}\text { mean } \\
\text { distance }(/) \\
\text { in nm }\end{array}$ & $\begin{array}{c}\text { Number of pairs } \\
\text { of } 1^{\text {st }} \\
\text { neighbours }\end{array}$ & $\begin{array}{c}\text { Number of pairs } \\
\text { of most distant } \\
\text { neighbours }\end{array}$ \\
\hline 1 to 14 & 29.1 & 2613 & 201 \\
\hline 1 to 6 & 29.5 & 1005 & 201 \\
\hline 6 to 11 & 28.8 & 1005 & 201 \\
\hline 10 to 16 & 29.0 & 1005 & 201 \\
\hline
\end{tabular}

measured (see Fig. 1). By averaging over the varous pairs of $m^{\text {th }}$ neighbours and over REM images (i.e. over time [7]) the mean distance between pairs, then the mean value of the relevant parameter $\left(u_{\imath}-u_{\imath+m}\right)^{2}$ were determined.

In order to check the homogeneity of the train we also determined $\left\langle\left(u_{\imath}-u_{\imath+m}\right)^{2}\right\rangle$ for three sub-sets of 6 steps within the 16 ones studied. The results are shown in Figure 3 . The determination of the error bars is explained below. Figure 4 shows the plot of $G(m)=$ $<\left(u_{2}-u_{\imath+m}\right)^{2}>$ versus $\log _{10}(m)$ up to $m=13$ and the relevant error bars. In addition, Table I displays the numbers of $m_{\mathrm{th}}$ neighbours that were taken into account for averaging and the mean step distances that were determined. From Figure 3 and Table I we conclude that the step train is fairly homogeneous and that our results are statistically significant.

The error bars were determined as follows: the experimentally measured value $U^{2}$ of $\left.<\left(u_{2}-u_{2+m}\right)^{2}\right\rangle$ is in fact an estimator of the actual (unknown) value $\sum^{2}$ [9]. If the distribution of the $\left(u_{\imath}-u_{\imath+m}\right)$ is Gaussian, then the standard deviation of $U^{2}$ is $\sum^{2} \sqrt{\left(2 / N_{m}\right)}$, where $N_{m}$ is the number of independent values used to determine $U^{2}$ [9]. It is reasonable to assume a Gaussian distribution for the distances between pairs of $m^{\text {th }}$ neighbours [7]. Since the measurements of the distances were independent the uncertainty was estimated to be $U^{2} \sqrt{\left(2 / N_{m}\right)}$.

\section{Discussion}

Figure 4 shows that a logarithmic dependence of $G$ is found up to $m=7$. This dependence also is found wherever a subset of 6 steps is selected within the train. Within the accuracy of the measurements the slope of $G$ versus $m$ is the same for all the subsets. Beyond $m=8$, a different regime is obeyed.

In the logarithmic regime the experimental value of the slope $S$ of $G$ is $S_{\exp }=1.11 \times 10^{2} \mathrm{~nm}^{2}$ If the value of $m$ is expressed in decimal logarithm. This regime should be characteristic of a roughened surface.

This expectation can be checked by comparing $S_{\exp }$ to the critical value $S_{\mathbf{R}} \equiv 2.302 \times$ $2\left(a_{\perp}\right)^{2} / \pi^{2}$, where $a_{\perp}$ is the kink length normal to the step direction [2]. At $T>T_{\mathrm{R}}, S_{\exp }$ must be larger than $S_{\mathrm{R}}$. Taking $a_{\perp}=0.333 \mathrm{~nm}$ yields $S_{\mathrm{R}}=5.18 \times 10^{-2} \mathrm{~nm}^{2}$, hence $S_{\exp } \gg S_{\mathrm{R}}$. Therefore we can conclude that our surface is rough.

We shall see later on that the measurements are made within the validity of the VGL model. Then $S_{\exp }$ can be compared to the theoretical value

$$
S=2.302\left(a_{\perp}\right)^{2} k T / \pi \sqrt{\eta \eta^{\prime}} \quad T>T_{\mathrm{R}}
$$


$\eta$ and $\eta^{\prime}$ are renormalised stiffnesses. Their expressions have been obtained by Masson [5] for energetic step interactions decaying as $1 / x^{2}$ :

$$
\eta=\frac{a_{\perp}^{2}}{a_{\|}}[\tilde{\beta}+\Delta]
$$

with

$$
\begin{gathered}
\Delta=\frac{1}{a_{\|} l^{2}} \frac{\partial^{2}}{\partial \varphi^{2}}\left[\frac{\pi^{2}}{24} k T b^{2}\left[1+\left(1+\frac{4 a_{\|} A}{k T b^{2}}\right)^{1 / 2}\right]^{2}\right]_{\varphi=0} \\
\eta^{\prime}=\frac{a_{\perp}^{2} a_{\|} \pi^{2} k^{2} T^{2}}{4 l^{4} \tilde{\beta}}\left[1+\left(1+\frac{4 A \tilde{\beta}}{k^{2} T^{2}}\right)^{1 / 2}\right]^{2}
\end{gathered}
$$

Here $\tilde{\beta}$ and $A$ are the step stiffness and the step interaction constant, respectively, $l$ is the mean interstep distance, $a_{\|}$and $a_{\perp}$ are the kink lengths parallel and perpendicular to the step direction $\left(a_{\|}=0.384 \mathrm{~nm} ; a_{\perp}=0.333 \mathrm{~nm}\right)$. In equation $(3), b^{2}$ is the "step diffusivity", i.e. the mean square displacement of a kink, which can be calculated from an atomistic model of the step [10], $b^{2}$ is a function of $\varphi$, the azimuthal angle of the step.

It is reasonable to use equations (2), (3) and (4) since the existence of $1 / x^{2}$ interactions is experimentally established [7]. The values of $A$ and $\tilde{\beta}$ are known for silicon at $1173 \mathrm{~K}$ [7]. However, no experimental value exists for $\Delta$. It can be calculated if a good model of the step structure is available. In this respect, Williams et al. have shown that the orientational phase diagram of silicon can be well explained by using a model of independent polykinks [10]. Using this model we have calculated $\Delta$. It turns out that $\Delta$ is much smaller than $\tilde{\beta}$ at $1173 \mathrm{~K}$ and can be neglected $\left(\Delta \approx 10^{-3} \tilde{\beta}\right)$. Then equations $(2)$ and $(3)$ show that the product $\eta \eta^{\prime}$ does not depend on $\tilde{\beta}$ itself. Instead, the relevant parameter is the product $A \tilde{\beta}$, which is directly obtained from the measurement of the terrace width distribution $\left(A \tilde{\beta}=4.6 \times 10^{-40} J^{2}\right.$ at $1173 \mathrm{~K})[7]$.

Using the aforementioned numerical values, equation (1) yields $S=1.10 \times 10^{2} \mathrm{~nm}^{2}$. The agreement with $S_{\exp }$ is excellent.

Note that VGL's logarithmic law is an asymptotic law, only valid when the parameter $\rho=m\left[\eta / \eta^{\prime}\right]^{1 / 4}$ is larger than 1 [2]. Using the calculated values for $\eta$ and $\eta^{\prime}$, it turns out that $\rho=53.7 \mathrm{~m}$. Thus $\rho$ is larger than 1 for any $m$ and the VGL formalism can be used.

Beyond $m=8$ the slope of $G$ increases and no simple logarithmic law can be found. This is no statistical artefact (Tab. I) and not due to an inhomogeneity of the train (Fig. 3). Therefore, another regime is reached. It looks as though the step train now behaved more like a onedimensional system. It may be a true physical effect, i.e. a breakdown of the approximations involved in the theoretical treatments. It may as well be an influence of , for instance, the finite length of the steps. However we must mention that the auto-correlation function of the steps, normal to the step mean direction (i.e. the function $\left\langle u_{\imath} \cdot u_{\imath+m}\right\rangle$ ) has also been measured as a function of $m$, in an independent manner, for the same train [8]. It turns out that this auto-correlation goes to zero for $m \geq 7$. This may not be coincidental. At the moment we have no clear-cut explanation and leave the question open. We also mention that Masson, too, could not fit her data by a single logarithmic law beyond $m=3$ for a $\mathrm{Cu}(1,1,11)$ vicinal [5]. 


\section{Conclusion}

In this paper the logarithmic divergence of the correlated height difference over a rough surface is demonstrated by meaningful statistical results. For a quantitative comparison with the VGL theory the only necessary quantity $(A \tilde{\beta})$ has been measured on the same sample. The agreement with the theory is excellent.

At large distances, however, the logarithmic law breaks down. This second regime could not be given a definite explanation.

\section{Acknowledgments}

We thank Prof. H.J.W. Zandvliet and Dr. P. E. Hegeman for supplying us with their unpublished results. We also thank Dr. D. Chatain and Prof. R. Kern for a critical reading of the manuscript.

\section{References}

[1] Nozı̀̀res P., Solids far from Equilıbrium, C. Godrèche, Ed. (Cambridge University Press, Cambridge, 1992) p. 1.

[2] Villain J., Grempel D.R. and Lapujoulade J,, J. Phys F. Met. Phys. 15 (1985) 809.

[3] Lapujoulade J., Surf. Sci. Reports 20 (1994) 191.

[4] Golberg J.L., Wang X.-S., Bartelt N.C. and Williams E.D., Surf. Scr. 249 (1991) L285

[5] Masson L., Thesis, Parıs (1994), unpublished.

[6] Hegeman P.E., Zandvliet H.J.W., Kip G.A.M., Kersten B.A. and Poelsema B., to be published.

[7] Alfonso C., Bermond J.M., Heyraud J.C. and Métois J.J., Surf. Sci. 262 (1992) 371.

[8] Alfonso C., Thesis, Marsellle (1992), unpublished.

[9] Bass J., Eléments de calcul des Probabilités (Masson, Parıs, 1974) p. 201.

[10] Williams E.D., Phaneuf R.J., Wei J., Bartelt N.C. and Einstein T.L., Surf. Sci. 294 (1993) 219; Surf. Sci. 310 (1994) 451. 